\title{
Physician self-reported treatment of brain metastases according to patients' clinical and demographic factors and physician practice setting
}

Marie-Adele S Kress ${ }^{1 *}$, Naren Ramakrishna², Solomon B Makgoeng ${ }^{3}$, Keith R Unger ${ }^{1}$ and Arnold L Potosky ${ }^{3}$

\begin{abstract}
Background: Limited data guide radiotherapy choices for patients with brain metastases. This survey aimed to identify patient, physician, and practice setting variables associated with reported preferences for different treatment techniques.

Method: 277 members of the American Society for Radiation Oncology (6\% of surveyed physicians) completed a survey regarding treatment preferences for 21 hypothetical patients with brain metastases. Treatment choices included combinations of whole brain radiation therapy (WBRT), stereotactic radiosurgery (SRS), and surgery. Vignettes varied histology, extracranial disease status, Karnofsky Performance Status (KPS), presence of neurologic deficits, lesion size and number. Multivariate generalized estimating equation regression models were used to estimate odds ratios.

Results: For a hypothetical patient with 3 lesions or 8 lesions, 21\% and 91\% of physicians, respectively, chose WBRT alone, compared with 1\% selecting WBRT alone for a patient with 1 lesion. 51\% chose WBRT alone for a patient with active extracranial disease or KPS=50\%. 40\% chose SRS alone for an 80 year-old patient with 1 lesion, compared to $29 \%$ for a 55 year-old patient. Multivariate modeling detailed factors associated with SRS use, including availability of SRS within one's practice (OR 2.22, 95\% Cl 1.46-3.37).

Conclusions: Poor prognostic factors, such as advanced age, poor performance status, or active extracranial disease, correspond with an increase in physicians' reported preference for using WBRT. When controlling for clinical factors, equipment access was independently associated with choice of SRS. The large variability in preferences suggests that more information about the relative harms and benefits of these options is needed to guide decision-making.
\end{abstract}

Keywords: Brain metastases, Stereotactic radiosurgery, Whole brain radiation therapy, Treatment patterns, Physician survey

\footnotetext{
* Correspondence: Marie-Adele.S.Kress@gunet.georgetown.edu

'Department of Radiation Oncology, Georgetown University Medical Center, 3800 Reservoir Road, Washington, D.C, USA

Full list of author information is available at the end of the article
} 


\section{Background}

Brain metastases are the most common intracranial tumor, occurring in $20-40 \%$ of cancer patients and accounting for $20 \%$ of cancer deaths annually [1]. Median survival is $1-2$ months with corticosteroids alone [2] or six months with whole brain radiation therapy (WBRT) $[3,4]$.

A major advance in the treatment of these patients was addition of surgery to WBRT for treatment of a single metastasis, which improved local control, distant intracranial control and neurologic survival compared to either modality alone [5,6]. A retrospective study demonstrated differential survival among patients undergoing WBRT according to recursive partitioning analysis (RPA) classes [7]; further prognostic refinements have incorporated histology and number of lesions [8].

More recently, stereotactic radiosurgery (SRS) has been used alone or with WBRT in patients with up to 4 metastases. When compared with WBRT alone, the addition of SRS has improved local control, functional autonomy and survival [5,9-11]. However, WBRT can have significant toxicities, including fatigue, drowsiness and suppressed appetite, and long-term difficulties with learning, memory, concentration, and depression [12-14]. The use of SRS alone controls limited disease and delays the time until WBRT is necessary for distant intracranial progression $[12,15,16]$.

In most clinical trials of therapies for brain metastases, patients have been selected on the basis of having few metastases, stable extracranial disease, and excellent performance status. In clinical practice, patients with brain metastases are a heterogeneous population, and decisionmaking requires the synthesis of multiple variables.

The objective of this survey of radiation oncologists was to identify patient factors, physician characteristics, and practice setting variables associated with physicians' preferred use of different techniques for treating brain metastases. This survey aimed to generate data that would allow physicians to: (1) compare their practice patterns to a national sample; (2) assess the influence of their practice environment on treatment choice; and (3) generate new hypotheses regarding appropriate treatment.

\section{Methods}

This project was approved by the IRB of Harvard Medical School. The survey was launched online, and physician members of the American Society for Therapeutic Radiology and Oncology (ASTRO) were emailed a recruitment letter. Eligibility criteria included respondent status as a U.S. or Canadian physician in the ASTRO database, valid email address, and current management of patients with brain metastases, as reflected by the screener question. Respondents linked directly to the survey from the email, and there was no incentive for survey participation.

\section{Data collection}

Data was de-identified and collected through the online survey tool for one month. We emailed surveys to 4357 physician members of ASTRO on September 26, 2008, and the survey was closed on October 26, 2008. 417 respondents answered at least one question, and 277 answered all demographic and clinical questions, for a response rate of 6\%. Despite our low response rate, physician respondents were representative of practicing radiation oncologists when compared to respondents to the American College of Radiology's (ACR) Survey of Radiation Oncologists. Our sample was similar to the ACR survey on selected characteristics such as sex (73\% male in our survey, 77\% in ACR), age (62\% ages $35-54$ in our survey, $65 \%$ in ACR) and being in private practice (52\% in our survey, $48 \%$ in ACR) [17]. However, it was not possible to assess interest in SRS or palliative care, or use of advanced technology, among those included in the ACR sample, which limits the comparison.

The survey was designed to: (1) describe radiation oncologists' patterns of treatment of patients with brain metastases; and (2) identify clinical, demographic, and practice setting factors associated with treatment patterns. To test physician practices, a series of short hypothetical clinical vignettes were developed to assess respondents' preferred treatment modalities. Vignettes have been demonstrated to be a valid study tool when compared with actual clinical practice patterns [18]. Treatment options for each vignette were identical: WBRT alone; WBRT with SRS; SRS alone; WBRT with surgery; or no treatment. We constructed 3 versions of a reference vignette: the first with 1 metastasis, the next with 3 metastases, and one with 8 metastases. Each reference vignette described a 55 year-old patient with non-small cell lung cancer, inactive extracranial disease, Karnofsky Performance Status (KPS) 80\%, and asymptomatic, small brain lesion(s). For each of these 3 vignettes, we asked about 6 additional patients, modifying a single variable: melanoma histology, active extracranial disease, KPS 50\%, presence of neurologic deficit, age of 80 years old, and large lesion (Figure 1).

Other survey items assessed factors related to the patient, physician, or practice setting. These questions included physician demographics, practice environment, availability of SRS, and opinions about the nature of intracranial disease and the toxicity of its treatment. A copy of our survey is included as supplementary material (Additional file 1: Appendix 1). Data regarding nonrespondents were not collected.

\section{Statistical analysis}

\section{Effects of patient clinical characteristics on treatment choices}

For the four category treatment choice responses (WBRT alone, WBRT with SRS, SRS alone, or surgery with WBRT), we used a series of multivariate binomial generalized 


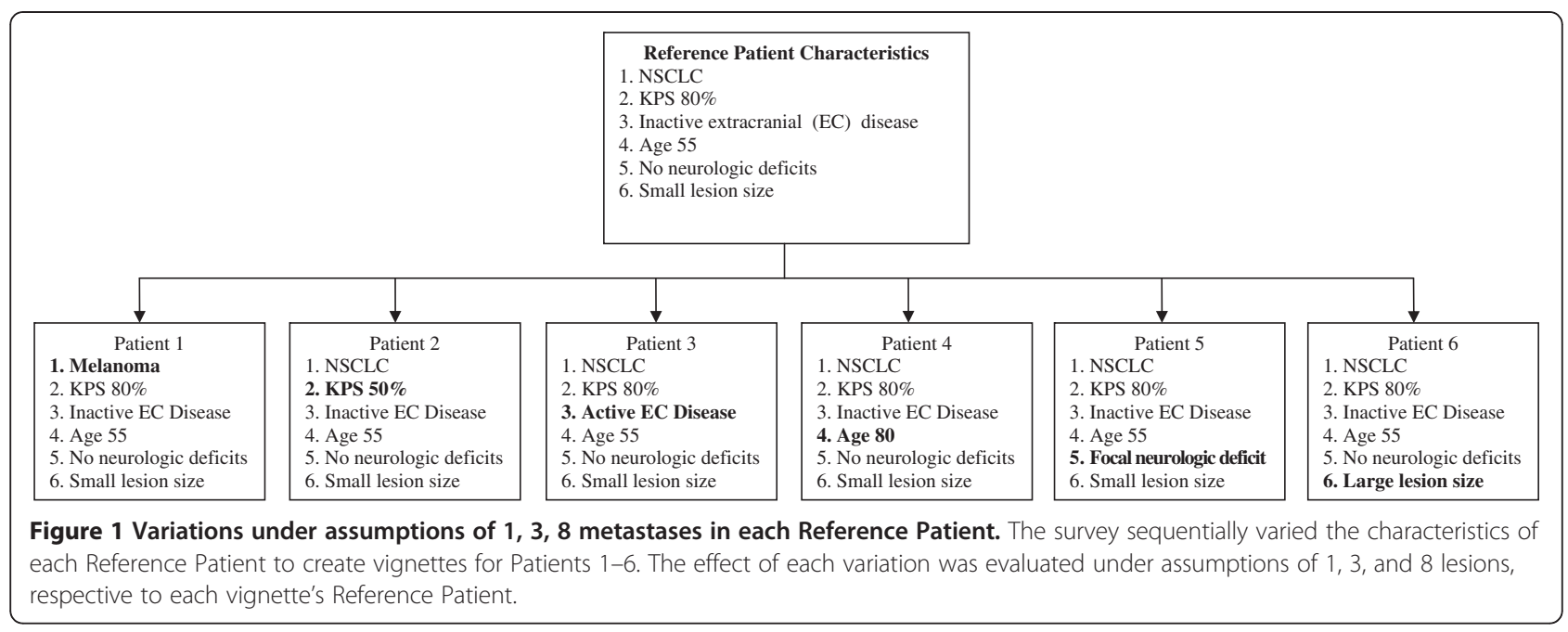

estimating equation (GEE) models to estimate odds ratios that measured the effects of each change in patients' clinical characteristics on the odds of each of 4 treatments choices relative to the odds of the remaining 3 alternatives. Since each vignette represented a repeat measurement on a physician, we considered treatment choices as correlated observations clustered within individual physicians. We used an exchangeable correlation structure to account for the correlation of physician responses between vignettes. Graphical techniques were used to assess model adequacy. We chose to use a series of binomial models to model a multicategory response because of the lack of available statistical software to implement multi-category GEE models with exchangeable correlation structure [19].

\section{Effects of patient \& physician characteristics on odds of including SRS}

We grouped treatment responses that included SRS (SRS or WBRT with SRS) and compared them with the 3 remaining alternatives as a combined reference group (WBRT, WBRT with surgery, or no treatment) in a binomial GEE model that included patient clinical, physician and practice setting characteristics as covariates. These groupings were created to allow for exploration of factors contributing to integrating advanced technology (SRS) into the treatment plan, despite the fact that each treatment approach may have different clinical indications, as explored through the above-detailed models. Working correlations and clustering were treated as in the previous models.

All parameter estimates were tested for statistical significance at the 0.05 level. SAS ${ }^{\circledR}$ software version 9.2 was used in all analyses.

\section{Results}

Physician demographics and practice environment The characteristics of our survey respondents are shown in Table 1. Sixty percent of respondents were in single- specialty group practices. Most practices were hospitalbased, academic (38\%) or private (30\%). Seventy-six percent of respondents treated 10-50 patients with brain metastases per year. Forty-four percent of respondents performed SRS, while $35 \%$ had a colleague at their institution who performed SRS. Sixty-one percent of respondents had LINACbased SRS, and $18 \%$ had no SRS equipment.

Physicians' responses to the 21 vignettes varied substantially (Table 2). Multivariable modeling revealed clinical factors influencing treatment selection (Tables 3, 4, 5; complete results in Additional file 2: Appendix 2).

\section{Whole brain radiation therapy alone}

WBRT alone was selected frequently, particularly for patients with 8 metastases. For the 80 year-old patient with 3 or 8 metastases, WBRT was commonly preferred (52\% and $96 \%$ vs. $21 \%$ and $91 \%$, respectively, for the 55 year old patient, Table 2). Even for a patient with a single metastasis, $56 \%$ of respondents preferred WBRT alone if that patient had KPS 50\%; 51\% would choose WBRT if the patient had active extracranial disease. In adjusted analyses, all of the clinical variables (melanoma histology, KPS 50\%, active extracranial disease, age of 80 years old, presence of focal neurologic deficits, and large lesion) were associated with a higher likelihood of respondents preferring WBRT alone versus either SRS alone (Table 3) or WBRT with SRS (Table 4), except for radioresistant histology.

\section{Addition of surgery}

For the reference patient with a single metastasis, $44 \%$ of respondents selected surgery with WBRT, although most respondents selected a non-operative approach that included SRS (26\% WBRT with SRS; 29\% SRS alone, for a total of $55 \%$ of respondents). When the reference vignette was revised to include the presence of focal neurologic deficits, the distribution of responses was 
Table 1 Distribution of Physician Characteristics ( $N=277$ )

\begin{tabular}{|c|c|c|}
\hline & $\mathbf{n}$ & $\%$ \\
\hline \multicolumn{3}{|l|}{ Total } \\
\hline No. of physicians with complete data & 277 & 100 \\
\hline \multicolumn{3}{|l|}{ Gender } \\
\hline Male & 202 & 73 \\
\hline Female & 75 & 27 \\
\hline \multicolumn{3}{|l|}{ Race/ethnicity } \\
\hline Non-White & 53 & 19 \\
\hline White & 224 & 81 \\
\hline \multicolumn{3}{|l|}{ Primary practice structure } \\
\hline Multi-specialty & 111 & 40 \\
\hline Single & 166 & 60 \\
\hline \multicolumn{3}{|l|}{ Primary practice environment } \\
\hline Office-based, private & 60 & 22 \\
\hline Office-based, academic & 14 & 5 \\
\hline Hospital-based, private & 84 & 30 \\
\hline Hospital-based, academic & 105 & 38 \\
\hline Veterans'/military hospital & 6 & 2 \\
\hline Other & 8 & 3 \\
\hline \multicolumn{3}{|l|}{ Years experience in specialty } \\
\hline Q1:0-5 & 70 & 25 \\
\hline Q2:6-14 & 77 & 28 \\
\hline Q3:15-20 & 61 & 22 \\
\hline Q4:21-40 & 69 & 25 \\
\hline \multicolumn{3}{|c|}{ Approx. annual count of brain metastases patients } \\
\hline$<10$ & 18 & 7 \\
\hline $10-50$ & 210 & 76 \\
\hline$>50$ & 49 & 18 \\
\hline
\end{tabular}

Frequency of patient follow-up

\begin{tabular}{lrr}
\hline At diagnosis only & 3 & 1 \\
\hline Through active treatment for brain metastases & 19 & 7 \\
\hline Through one post-treatment visit & 95 & 34 \\
\hline Throughout the remaining course of their disease & 152 & 55 \\
\hline Other & 8 & 3 \\
\hline
\end{tabular}

${ }^{1}$ Respondents were permitted to select more than one modality.

${ }^{2}$ Personal experience includes the respondent personally being treated for brain metastases, or having had a friend or family member treated for brain metastases.

* Stereotactic radiosurgery.

similar for those with 1 lesion, with $48 \%$ of respondents preferring surgery with WBRT. When considering patients with a single, large lesion, the percent of respondents choosing surgery with WBRT increased from $44 \%$ to $63 \%$. After adjusting for all other clinical factors, respondents were more likely to choose surgery with WBRT rather than WBRT alone for patients with large versus smaller lesions (OR=1.9, 95\% CI 1.3-2.8). For 3 or 8 lesions, age 80 , active extracranial disease, and KPS 50\%, respondents were more likely to choose WBRT alone than surgery with WBRT (Additional file 2: Appendix 2). Melanoma histology and presence of neurologic deficits did not correlate with respondents' selections.

\section{Addition of stereotactic radiosurgery}

SRS was commonly preferred by respondents for patients with 3 lesions (23\% SRS alone; 54\% SRS with WBRT, Table 2), and it largely replaced the use of surgery for the older patient with a single lesion $(25 \%$ WBRT with SRS; $40 \%$ chose SRS alone). Presence of neurological deficits and large lesion size were associated with physicians' preference for WBRT with SRS over SRS alone (Table 5). However, older age, poorer performance status and melanoma histology were associated with less frequent selection of WBRT with SRS versus SRS alone.

\section{Use of stereotactic radiosurgery}

Multivariable analysis was performed to identify which factors were independently associated with including SRS as part of treatment (SRS or WBRT with SRS) compared to all other treatment choices (WBRT, WBRT with surgery, no treatment), adjusting for all other characteristics in Table 6. Number of metastases was strongly associated with treatment preferences: after adjustment for all other factors in the model, respondents were significantly more likely to favor SRS for 3 lesions than for 1 ( $\mathrm{OR}=2.22,95 \% \mathrm{CI} 1.96-2.51)$, and physicians were 5 times less likely to choose an approach that included SRS for a patient with 8 lesions relative to patients with 1 lesion (OR=0.19, 95\% CI 0.15-0.23).

Across all clinical vignettes, after adjusting for all other factors, poor KPS $(\mathrm{OR}=0.38,95 \%$ CI $0.31-0.46)$, active extracranial disease $(\mathrm{OR}=0.56,95 \%$ CI $0.47-0.65)$, and large lesion ( $\mathrm{OR}=0.58,95 \% \mathrm{CI}$ 0.47-0.71) remained strongly negatively associated with the choice of SRS, while melanoma histology ( $\mathrm{OR}=2.84,95 \% \mathrm{CI} 2.45-3.29)$ and advanced age $(\mathrm{OR}=1.23,95 \% \mathrm{CI} 1.07-1.41)$ were positively associated with choice of SRS. Physician access was the strongest factor associated with choosing SRS as part of treatment. Respondents with SRS capability in their own practice were more likely to favor its use for hypothetical patients than those without it $(\mathrm{OR}=2.22$, 95\% CI 1.46-3.37). As expected, those physicians who personally used SRS were more likely to recommend it than those who did not have it or use it personally in their practice (OR=3.57, 95\% CI 2.42-5.26). Patient volume and physician seniority were examined, but were not associated with SRS use.

\section{Discussion}

Treatment of patients with brain metastases is heterogeneous. WBRT is a standard therapy, with the addition of 
Table 2 Unadjusted Response (in \%) Among Radiation Oncologist (N=277)

\begin{tabular}{|c|c|c|c|c|c|c|c|c|c|c|c|c|}
\hline & \multicolumn{12}{|l|}{ Lesions } \\
\hline & \multicolumn{4}{|l|}{1} & \multicolumn{4}{|l|}{3} & \multicolumn{4}{|l|}{8} \\
\hline & \multicolumn{4}{|c|}{$\begin{array}{l}\text { Treatment } \\
\text { Decisions (\%) }\end{array}$} & \multicolumn{4}{|c|}{$\begin{array}{l}\text { Treatment } \\
\text { Decisions (\%) }\end{array}$} & \multicolumn{4}{|c|}{$\begin{array}{l}\text { Treatment } \\
\text { Decisions (\%) }\end{array}$} \\
\hline & WBRT $^{*}$ & WBRT+SRS & SRSt & SURG+WBRT & WBRT & WBRT+SRS & SRS & SURG+WBRT & WBRT & WBRT+SRS & SRS & SURG+WBRT \\
\hline \multicolumn{13}{|l|}{ Patient Characteristics } \\
\hline 1. Reference patient & 1 & 26 & 29 & 44 & 21 & 54 & 23 & 2 & 91 & 7 & 3 & 0 \\
\hline 2. Melanoma Metastasis & 1 & 17 & 46 & 36 & 18 & 44 & 35 & 3 & 82 & 11 & 7 & 0 \\
\hline 3. KPS 50 & 56 & 17 & 24 & 3 & 84 & 7 & 8 & 1 & 96 & 2 & 2 & 0 \\
\hline 4. Extracranial Disease & 51 & 19 & 23 & 7 & 73 & 15 & 11 & 0 & 94 & 3 & 2 & 0 \\
\hline 5. Age 80 & 25 & 25 & 40 & 10 & 52 & 24 & 23 & 0 & 96 & 2 & 2 & 0 \\
\hline $\begin{array}{l}\text { 6. Focal } \\
\text { Neurological } \\
\text { Deficits }\end{array}$ & 11 & 25 & 17 & 48 & 34 & 41 & 11 & 13 & 89 & 6 & 2 & 4 \\
\hline 7. $3 \mathrm{~cm}$ Brain Metastasis & 11 & 22 & 5 & 63 & 42 & 29 & 2 & 27 & 72 & 16 & 0 & 11 \\
\hline
\end{tabular}

${ }^{1}$ Abbreviations as follows: Whole Brain Radiation Therapy (WBRT); Whole Brain Radiation Therapy with Stereotactic Radiosurgery (WBRT+SRS); Stereotactic Radiosurgery (SRS); Surgery with Whole Brain Radiation Therapy (SURG+WBRT).

${ }^{2}$ The reference patient was a 55 year-old patient with non-small cell lung cancer, inactive extracranial disease, KPS 80\%, and an asymptomatic, small brain lesion.

${ }^{3}$ Patient characteristics were varied sequentially with each patient differing by a single characteristic from the reference patient as shown in Figure 1.

* Whole brain radiation therapy.

+ Stereotactic radiosurgery. 
Table 3 Odds Ratios for Choice of WBRT ${ }^{*}$ alone versus SRSt Alone

\begin{tabular}{lll}
\hline WBRT* vs. SRS & OR $(\mathbf{9 5} \% \mathbf{C l})+\dagger^{1}$ & $\mathbf{P}$ \\
\hline Lesions & & \\
\hline 1 (referent) & 1.00 & $<.0001$ \\
\hline 3 & $3.5(2.7,4.4)$ & $<.0001$ \\
\hline 8 & $59.8(29.1,122.8)$ & \\
\hline Age & & $<.0001$ \\
\hline 55 (referent) & 1.00 & \\
\hline 80 & $2.0(1.5,2.6)$ & \\
\hline Extracranial Disease & & $<.0001$ \\
\hline None (referent) & 1.00 & \\
\hline Active & $5.5(3.7,8.1)$ & \\
\hline Focal Neurological Deficits & & $<.0001$ \\
\hline Asymptomatic (referent) & 1.00 & $<.0001$ \\
\hline Symptomatic & $2.7(2.0,3.7)$ & \\
\hline Performance Status $§$ & & $<.0001$ \\
\hline 80 (referent) & 1.00 & \\
\hline 50 & $6.6(4.4,9.9)$ & \\
\hline Lesion Size & 1.00 & \\
\hline Small (referent) & $8.1(5.3,12.4)$ & \\
\hline Large & & \\
\hline Melanoma & $0.5(0.4,0.6)$ & \\
\hline NSCLCI (referent) & & \\
\hline Melanoma & & \\
\hline & & \\
\hline
\end{tabular}

surgery or SRS to WBRT, or SRS used alone, reserved for selected patients on the basis of their clinical characteristics. One potential advantage of local therapy may be avoiding the toxicity of WBRT [12-14]. However, SRS, when used alone, has several disadvantages. SRS alone has been shown to be inferior to the combination of SRS with WBRT for durable local control and distant intracranial control [15]. When studying patients initially undergoing any local therapy - surgery or SRS - more patients required salvage if treated without WBRT [20]. Long-term cognitive outcomes have been shown to be more closely correlated with intracranial progression than with treatment modality, emphasizing the significance of intracranial control over shortterm side effects $[21,22]$.

Given the limited scope of current studies and the variability in outcomes, National Comprehensive Cancer Network (NCCN) guidelines allow for a wide range of treatment options including WBRT, surgical resection, or SRS, alone or in combinations [23]. Previous reviews of treatment patterns have demonstrated stable rates of surgery since the 1980s, with an increasing use of SRS [24]. Despite clinical trials limiting eligible patients to those with limited central nervous system disease, a recent survey demonstrated that more than half of physician respondents would consider using SRS as an initial treatment for patients with 5 or more intracranial lesions [25]. The increased utilization of SRS as well as the persistent heterogeneity in practice may be due to the time of dissemination of research into clinical practice, or the time to purchase and adoption of new technologies.

With mixed evidence and a heterogeneous patient population, treatment decision-making is complex. Significantly, our study demonstrates that although clinical factors, such as number of lesions and patient age, affected treatment selection, physician practice environment had a strong, independent effect on the use of SRS.

Factors related to the patient's clinical condition affected treatment selection. There was increased use of WBRT for increasing number of lesions, which is consistent with the lack of evidence to support the use of local techniques for patients with numerous metastases. However, we observed that a substantial proportion of physicians still chose SRS as part of their approach for patients with multiple lesions, particularly for patients with 3 lesions. The increased use of SRS with 3 lesions as compared with 1 was possibly due to the use of surgery for a substantial proportion of patients

Table 4 Odds Ratios for Choice of WBRT alone versus WBRT with SRS

\begin{tabular}{lll}
\hline WBRT vs WBRT+SRS & OR $(\mathbf{9 5} \% \mathbf{C l})$ & $\mathbf{P}$ \\
\hline Lesions & & \\
\hline 1 (referent) & 1.00 & $<.0001$ \\
\hline 3 & $2.5(2.0,3.1)$ & $<.0001$ \\
\hline 8 & $37.0(24.6,55.5)$ & \\
\hline Age & & $<.0001$ \\
\hline 55 (referent) & 1.00 & \\
\hline 80 & $4.6(3.5,6.1)$ & \\
\hline Extracranial Disease & & $<.0001$ \\
\hline None (referent) & 1.00 & \\
\hline Active & $11.4(8.2,15.9)$ & \\
\hline Focal Neurological Deficits & & \\
\hline Asymptomatic (referent) & 1.00 & $<.0001$ \\
\hline Symptomatic & $1.9(1.5,2.3)$ & \\
\hline Performance Status $\S$ & & $<.0001$ \\
\hline 80 (referent) & 1.00 & \\
\hline 50 & $18.0(12.5,25.8)$ & \\
\hline Lesion Size & & \\
\hline Small (referent) & 1.00 & \\
\hline Large & $1.9(1.4,2.6)$ & \\
\hline Melanoma & & \\
\hline NSCLC (referent) & & \\
\hline Melanoma & & \\
\hline
\end{tabular}


Table 5 Odds Ratios for Choice of WBRT with SRS versus SRS alone

\begin{tabular}{lll}
\hline WBRT+SRS vs SRS & OR $(\mathbf{9 5} \% \mathbf{C l})$ & P \\
\hline Lesions & & \\
\hline 1 (referent) & 1.00 & $<.0001$ \\
\hline 3 & $2.1(1.7,2.6)$ & 0.0002 \\
\hline 8 & $6.7(2.4,18.5)$ & \\
\hline Age & & \\
\hline 55 (referent) & 1.00 & $<.0001$ \\
\hline 80 & $0.6(0.5,0.7)$ &
\end{tabular}

\begin{tabular}{lll}
\hline Extracranial Disease & & \\
\hline None (referent) & 1.00 & 0.6576 \\
\hline Active & $0.9(0.7,1.3)$ & \\
\hline Focal Neurological Deficits & & \\
\hline Asymptomatic (referent) & 1.00 & 0.0021 \\
\hline Symptomatic & $1.4(1.1,1.7)$ & \\
\hline Performance Status $\S$ & & 0.0101 \\
\hline 80 (referent) & 1.00 & \\
\hline 50 & $0.7(0.5,0.9)$ & \\
\hline
\end{tabular}

Lesion Size

Small (referent) $\quad 1.00$

\begin{tabular}{lll}
\hline Large & $5.6(3.2,9.8)$ & $<.0001$
\end{tabular}

\section{Melanoma}

NSCLCI (referent)

1.00

Melanoma

$0.5(0.4,0.6)$

$<.0001$

\section{Notes}

Odds ratios (OR) are quoted with their $95 \%$ confidence intervals in

parentheses. "*" Denotes significant odds ratios at the 0.05 level.

The odds ratios compare odds of choosing each given treatment, with the

odds of choosing the treatments serving as reference categories.

* Whole brain radiation therapy.

† Stereotactic radiosurgery.

t† Confidence intervals.

$\S$ Karnofsky Performance Status.

I Non-Small Cell Lung Cancer.

with 1 lesion, and due to the use of SRS combined with WBRT in patients with 3 lesions. Interestingly, physicians overall selected WBRT for patients with 1,3 , or 8 lesions more often for patients who were frail (increased age, low KPS) and might suffer increased morbidity from WBRT. This finding was unexpected, since WBRT has been shown to cause side effects that might be difficult for frail patients with limited life expectancy to tolerate, such as increasing fatigue, worsening physical function, and deterioration of appetite $[7,14,26]$. Additional clinical factors may influence treatment selection, but were not addressed in this study, including tumor location and surgical accessibility; additional treatment options not evaluated include the use of SRS in combination with surgery, chemotherapy, and the role of hospice.

Practice environment and clinical expertise also influenced the use of SRS, even when controlling for clinical factors. Although practice type was not associated with the preference for SRS, the availability of SRS was significantly associated with its use, indicating that patients are more likely to receive this treatment if the physician they see practices it herself or has it available within her practice. This pattern of care could lead to under- or over-utilization of SRS: patients may have treatment guided more by a provider's practice than by the patient's clinical condition. Previous studies have demonstrated the association of physician specialization, board certification, treatment volume and time in practice with other cancer-related treatment decisions $[27,28]$. For example, diagnostic imaging use has increased when such imaging is performed at a self-referred facility [29]. Similarly, radiation oncologists may be prescribing complex treatment approaches more frequently when they have access to the facilities or equipment. Alternatively, this propensity for increased use of SRS with easy access may relate to physicians' familiarity with their own clinical outcomes when using new technology. Our respondents may also have rates of access to SRS that are not comparable to those available nationwide, since the ACR survey did not report on the availability of SRS equipment.

Our study has several limitations due to its reliance on physician self-report as a proxy for practice, its timing, and the limited number of respondents. Clinical scenarios were hypothetical and treatment options were limited. Although physician surveys have shown a strong correlation between vignettes and actual practice [18], further objective validation of these data would be desirable, as the vignettes used in this survey were novel. Respondents to this survey were dominantly radiation oncologists, whose treatment decisions may be greatly impacted by other members of the inter-disciplinary oncology team not represented in this survey. Rates of radiosurgery utilization more than doubled between 2000 and 2005, so continued increases in the use of radiosurgery could have occurred since the completion of this survey [30]. Additional research has been published since 2008 that may have resulted in further shifts in practice patterns.

The limited number of respondents to our survey limits the generalizability of our findings. The response rate of $6 \%$ may indicate that the practice patterns outlined in this study are specific to a subgroup of clinicians with particular interest or expertise in radiosurgery and may not be indicative of global patterns of care. Although respondents were similar to those in the ACR survey, the comparison is limited due to the nature of the variables available; key issues, such as expertise with SRS or volume of patients brain metastases, were not available in the ACR survey for comparison. However, ours is the first study to document practice patterns using vignettes in this clinical setting. 
Table 6 Results of logistic regression model showing the reported use of SRS* as part of treatment for brain metastases according to multiple clinical, sociodemographic, and practice setting factors ${ }^{2}$

\begin{tabular}{|c|c|c|}
\hline & Including SRS ${ }^{1}$ & p-value \\
\hline \multicolumn{3}{|l|}{ Lesions } \\
\hline 1 (reference) & 1.00 & \\
\hline 3 & $2.22(1.96-2.51)$ & $<.0001$ \\
\hline 8 & $0.19(0.15-0.23)$ & $<.0001$ \\
\hline \multicolumn{3}{|l|}{ Karnofsky Performance Status } \\
\hline 80 (reference) & 1.00 & \\
\hline 50 & $0.38(0.31-0.46)$ & $<.0001$ \\
\hline \multicolumn{3}{|l|}{ Tumor Characteristics } \\
\hline Lung cancer (reference) & 1.00 & \\
\hline Melanoma histology & $2.84(2.45-3.29)$ & $<.0001$ \\
\hline \multicolumn{3}{|l|}{ Extracranial disease } \\
\hline No extracranial disease (reference) & 1.00 & \\
\hline Active extracranial disease & $0.56(0.47-0.65)$ & $<.0001$ \\
\hline \multicolumn{3}{|l|}{ Age } \\
\hline 55 (reference) & 1.00 & \\
\hline 80 & $1.23(1.07-1.41)$ & 0.0034 \\
\hline \multicolumn{3}{|l|}{ Focal neurological deficits } \\
\hline None (reference) & 1.00 & \\
\hline Present & $0.99(0.85-1.14)$ & 0.8492 \\
\hline \multicolumn{3}{|l|}{ Lesion size } \\
\hline Small (reference) & 1.00 & \\
\hline Large & $0.58(0.47-0.71)$ & $<.0001$ \\
\hline \multicolumn{3}{|l|}{ Race } \\
\hline Other (reference) & 1.00 & \\
\hline White & $1.13(0.83-1.52)$ & 0.4415 \\
\hline \multicolumn{3}{|l|}{ Gender } \\
\hline Male (reference) & 1.00 & \\
\hline Female & $1.07(0.81-1.40)$ & 0.6287 \\
\hline \multicolumn{3}{|l|}{ Specialization of Practice Setting } \\
\hline Multispecialty (reference) & 1.00 & \\
\hline Single & $1.07(0.82-1.39)$ & 0.6036 \\
\hline \multicolumn{3}{|l|}{ Access to SRS } \\
\hline None (reference) & 1.00 & \\
\hline Personal use & $3.57(2.42-5.26)$ & $<.0001$ \\
\hline Available in practice & $2.22(1.46-3.37)$ & 0.0002 \\
\hline \multicolumn{3}{|l|}{ WBRT + Adverse Effects Severity } \\
\hline None (reference) & 1.00 & \\
\hline At least minimal severity & $0.55(0.40-0.77)$ & 0.0004 \\
\hline \multicolumn{3}{|l|}{ SRS Adverse Effects Severity } \\
\hline None (reference) & 1.00 & \\
\hline At least minimal severity & $0.90(0.53-1.51)$ & 0.6804 \\
\hline Personal Experience with Brain Metas & & \\
\hline
\end{tabular}

Table 6 Results of logistic regression model showing the reported use of SRS ${ }^{*}$ as part of treatment for brain metastases according to multiple clinical, sociodemographic, and practice setting factors ${ }^{2}$ (Continued)

\begin{tabular}{|c|c|c|}
\hline Some personal (reference) ${ }^{3}$ & 1.00 & \\
\hline Patients only & $1.10(0.81-1.50)$ & 0.5369 \\
\hline \multicolumn{3}{|c|}{$\begin{array}{l}1 \text { Including SRS was defined as either use of SRS alone or with Whole Brain } \\
\text { Radiation Therapy (WBRT). } \\
{ }^{2} \text { The reference patient was a } 55 \text { year-old patient with non-small cell lung } \\
\text { cancer, inactive extracranial disease, KPS } 80 \% \text {, and an asymptomatic, small } \\
\text { brain lesion. } \\
{ }^{3} \text { Personal experience includes the respondent personally being treated for } \\
\text { brain metastases, or having had a friend or family member treated for brain } \\
\text { metastases. } \\
\text { * Stereotactic radiosurgery. } \\
+ \text { Whole brain radiation therapy. }\end{array}$} \\
\hline
\end{tabular}

\section{Conclusions}

Although many patients with cancer develop brain metastases, there is little data to guide treatment decisions. Our study demonstrates the significant heterogeneity among radiation oncologists in general clinical practice even for patients with identical clinical characteristics. Certain non-clinical factors, such as access to SRS, appear to be key drivers of use of advanced technology. This finding raises the question about what additional incentives could be driving treatment selection in the absence of gold-standard evidence of the superiority of a single approach over other alternatives. Our findings from this survey also underscore the likely uncertainty or disagreement that may exist among radiation oncologists about the relative harms and benefits of different treatment approaches. This uncertainty is likely related to the lack of prospective randomized studies that compare specific single- and multi-modality approaches for the treatment of brain metastases. More research is needed that directly compares the effectiveness of these approaches for a variety of different clinical circumstances. It would also be important to investigate underlying non-clinical factors, such as physician environment, reimbursement, and technology access, which likely contribute to observed heterogeneity of care for patients with brain metastases.

\section{Additional files}

Additional file 1: Appendix 1. Complete physician survey.

Additional file 2: Appendix 2. Odds Ratios and Confidence Intervals

Comparing the Odds of Treatment Choices for Different Patient

Characteristics.

\section{Abbreviations}

WBRT: Whole brain radiation therapy; SRS: Stereotactic radiosurgery; KPS: Karnofsky performance status; RPA: Recursive partitioning analysis; ASTRO: American society for therapeutic radiation oncology; ACR: American 
college of radiology; GEE: Generalized estimating equation; NCCN: National comprehensive cancer network.

\section{Competing interests}

Dr. Ramakrishna has received speaker's honoraria from and prepared educational materials for Brainlab Ag, Heimstetten, Germany. The remaining authors have no conflicts of interest to disclose.

\section{Authors' contributions}

NR and MK conceived of the study, designed the survey, and completed data collection. MK, KU, SM, and AP performed statistical analysis and data interpretation. MK, SM, and AP drafted the manuscript. All authors read and approved the final manuscript.

\section{Acknowledgements}

Neil Samuel Ghiso Foundation Fellowship.

\section{Author details}

'Department of Radiation Oncology, Georgetown University Medical Center, 3800 Reservoir Road, Washington, D.C, USA. ${ }^{2}$ Department of Radiation Oncology, MD Anderson Cancer Center Orlando, Orlando, Florida, USA. ${ }^{3}$ Cancer Control Program, Lombardi Comprehensive Cancer Center, Georgetown University Medical Center, Washington D.C, USA.

Received: 10 August 2012 Accepted: 11 October 2012

Published: 8 November 2012

\section{References}

1. Nussbaum ES, Djalilian HR, Cho KH, et al: Brain metastases. Histology, multiplicity, surgery, and survival. Cancer 1996, 78:1781-1788.

2. Weissman DE: Glucocorticoid treatment for brain metastases and epidural spinal cord compression: a review. J Clin Oncol 1988, 6:543-551.

3. Borgelt $B$, Gelber $R$, Kramer $S$, et al: The palliation of brain metastases: final results of the first two studies by the Radiation Therapy Oncology Group. Int J Radiat Oncol Biol Phys 1980, 6:1-9.

4. Rades D, Kieckebusch $S$, Haatanen $T$, et al: Surgical resection followed by whole brain radiotherapy versus whole brain radiotherapy alone for single brain metastasis. J Radiat Oncol Biol Phys 2008, 70:1319-1324.

5. Patchell RA, Tibbs PA, Regine WF, et al: Postoperative radiotherapy in the treatment of single metastases to the brain: a randomized trial. JAMA 1998, 280:1485-1489.

6. Patchell RA, Tibbs PA, Walsh JW, et al: A randomized trial of surgery in the treatment of single metastases to the brain. N Engl J Med 1990, 322:494-500.

7. Gaspar L, Scott C, Rotman M, et al: Recursive partitioning analysis (RPA) of prognostic factors in three Radiation Therapy Oncology Group (RTOG) brain metastases trials. Int J Radiat Oncol Biol Phys 1997, 37:745-751.

8. Sperduto PW, Chao ST, Sneed PK, et al: Diagnosis-specific prognostic factors, indexes, and treatment outcomes for patients with newly diagnosed brain metastases: a multi-institutional analysis of 4,259 patients. Int J Radiat Oncol Biol Phys 2010, 77:655-661.

9. Kondziolka D, Patel A, Lunsford LD, et al: Stereotactic radiosurgery plus whole brain radiotherapy versus radiotherapy alone for patients with multiple brain metastases. Int I Radiat Oncol Biol Phys 1999, 45:427-434.

10. Sanghavi SN, Miranpuri SS, Chappell R, et al: Radiosurgery for patients with brain metastases: a multi-institutional analysis, stratified by the RTOG recursive partitioning analysis method. Int J Radiat Oncol Biol Phys 2001, 51:426-434.

11. Andrews DW, Scott CB, Sperduto PW, et al: Whole brain radiation therapy with or without stereotactic radiosurgery boost for patients with one to three brain metastases: phase III results of the RTOG 9508 randomised trial. Lancet 2004, 363:1665-1675.

12. Chang EL, Wefel JS, Hess KR, et al: Neurocognition in patients with brain metastases treated with radiosurgery or radiosurgery plus whole-brain irradiation: A randomised controlled trial. Lancet Oncology 2009, 10:1037-1044.

13. Kondziolka D, Niranjan A, Flickinger JC, et al: Radiosurgery with or without whole-brain radiotherapy for brain metastases: The patients' perspective regarding complications. Am J Clin Oncol 2005, 28:173-179.

14. Chow E, Davis L, Holden L, et al: Propsective assessment of patient-rated symptoms following whole brain radiotherapy for brain metastases. Journal of Pain and Symptom Management 2005, 30:19-23.
15. Aoyama $\mathrm{H}$, Shirato $\mathrm{H}$, Tago $M$, et al: Stereotactic radiosurgery plus whole-brain radiation therapy vs stereotactic radiosurgery alone for treatment of brain metastases: a randomized controlled trial. JAMA 2006, 295:2486-2491.

16. Sneed PK, Suh JH, Goetsch SF, et al: A multi-institutional review of radiosurgery alone vs. radiosurgery with whole brain radiotherapy as the initial management of brain metastases. Int I Radiat Oncol Biol Phys 2002, 53:519-526.

17. Lewis RS, Sunshine JH: Radiation Oncologists in the United States. Int J Radiat Oncol Biol Phys 2007, 69:518-527.

18. Peabody JW, Luck J, Glassman P, et al: Measuring the quality of physician practice by using clinical vignettes: a prospective validation study. Ann Intern Med 2004, 141:771-780.

19. Kuss O, McLerran D: A note on the estimation of the multinomial logistic model with correlated responses in SAS Computer Methods and Programs. Biomedicine 2007, 87:262-269.

20. Kocher M, Soffiette R, Abacioglu U, et al: Adjuvant whole-brain radiotherapy versus observation after radiosurgery or surgical resection of one to three cerebral metastases: results of the EORTC 22952-26001 study. J Clin Oncol 2011, 29:134-141.

21. Aoyama $\mathrm{H}$, Tago $\mathrm{M}$, Kato $\mathrm{N}$, et al: Neurocognitive function of patients with brain metastasis who received either whole brain radiotherapy plus stereotactic radiosurgery or radiosurgery alone. Int I Radiat Oncol Biol Phys 2007, 68:1388-1395.

22. Regine WF, Scott C, Murray K, et al: Neurocognitive outcome in brain metastases patients treated with accelerated-fractionation vs. accelerated-hyperfractionated radiotherapy: An analysis from Radiation Therapy Oncology Group Study 91-04. Int J Radiat Oncol Biol Phys 2001, 51:711-717.

23. National Comprehensive Cancer Network: NCCN Clinical Practice Guidelines in Oncology (NCCN Guidelines): Central Nervous System Cancers Version 2.2011.: National Comprehensive Cancer Network; 2001

24. Nieder C, Spanne O, Mehta MP, et al: Presentation, patterns of care, and survival in patients with brain metastases: what has changed in the last 20 years?. Cancer 2010, Epub ahead of print.

25. Knisely JP, Yamamoto M, Gross CP, et al: Radiosurgery alone for 5 or more brain metastases: expert opinion survey. J Neurosurg 2010, 113:84-89.

26. Pesce GA, Klingbiel D, Ribi K, et al: Outcome, quality of life and cognitive function of patients with brain metastases from non-small cell lung cancer treated with whole brain radiotherapy combined with gefitinib or temozolomide. A randomised phase II trial of the Swiss Group for Clinical Cancer Research (SAKK 70/03). Eur J Cancer 2012, 48:377-384.

27. Wasif N, Tamurian RM, Christensen S, et al: Influence of Specialty and Clinical Experience on Treatment Sequencing in the Multimodal Management of Soft Tissue Extremity Sarcoma. Ann Surg Oncol 2011, 19:504-510.

28. Chuah TK, Lee T, Wirtzfeld D, et al: Management of primary rectal cancer by surgeons in Atlantic Canada: results of a regional survey. Can I Surg 2010, 53:396-402.

29. Kilani RK, Paxton BE, Stinnett SS, et al: Self-referral in medical imaging: a meta-analysis of the literature. J Am Coll Radiol 2011, 8:469-476.

30. Halasz LM, Weeks JC, Neville BA, et al: Use of Stereotactic Radiosurgery For Brain Metastases: A SEER-Medicare Analysis:. Poster Presentation, ASTRO; 2011.

doi:10.1186/1748-717X-7-188

Cite this article as: Kress et al:: Physician self-reported treatment of brain metastases according to patients' clinical and demographic factors and physician practice setting. Radiation Oncology 2012 7:188. 